\title{
Archives
}

\section{Mot de la rédactrice en chef invitée}

\section{DIANE BAILLARGEON}

Volume 46, numéro 2, 2017

URI : https://id.erudit.org/iderudit/1040375ar

DOI : https://doi.org/10.7202/1040375ar

Aller au sommaire du numéro

Éditeur(s)

Association des archivistes du Québec (AAQ)

ISSN

0044-9423 (imprimé)

2369-9256 (numérique)

Découvrir la revue

Citer ce document

Baillargeon, D. (2017). Mot de la rédactrice en chef invitée. Archives, 46(2), 5-6. https://doi.org/10.7202/1040375ar

Ce document est protégé par la loi sur le droit d'auteur. L'utilisation des services d'Érudit (y compris la reproduction) est assujettie à sa politique d'utilisation que vous pouvez consulter en ligne.

https://apropos.erudit.org/fr/usagers/politique-dutilisation/
Cet article est diffusé et préservé par Érudit.

Érudit est un consortium interuniversitaire sans but lucratif composé de l’Université de Montréal, l’Université Laval et l'Université du Québec à Montréal. Il a pour mission la promotion et la valorisation de la recherche. https://www.erudit.org/fr/ 


\section{MOT DE LA RÉDACTRICE EN CHEF INVITÉE}

L'année 2016 a marqué le $50^{\mathrm{e}}$ anniversaire de la Division de la gestion de documents et des archives (DGDA). Créé en 1966 sous le nom de Service des archives, il est le troisième service des archives à être organisé dans les universités, après McGill en 1960 et Laval en 1964. Au départ, restreint à la gestion des documents du Secrétariat général, son mandat s'élargit pour englober l'ensemble de l'Université dès le début des années 1970.

Au fil des ans, I'influence du Service des archives sur le développement de l'archivistique québécoise se fait de plus en plus sentir. Ses dirigeants forment le fer de lance de la mise en œuvre d'une archivistique intégrée au Québec avec les François Beaudin, Carol Couture, Jacques Ducharme, Jean-Yves Rousseau et Denys Chouinard. À I'aube de I'an 2000, Claude Minotto en devient le directeur et insuffle un nouveau dynamisme à l'équipe en investissant le champ des archives numériques.

Les artisans du Service des archives de l'Université de Montréal ont eu le souci de faire connaître les principes qu'ils ont mis en application dans leur pratique quotidienne. En témoignent les nombreuses publications du Service des archives dont le très populaire traité Les archives au XX siècle. Une réponse aux besoins de l'administration et de la recherche, de Carol Couture et Jean-Yves Rousseau, ainsi que l'ouvrage Le traitement d'un fonds d'archives: ses documents historiques, de Denys Chouinard et Michel Champagne, pour ne nommer que ceux-là.

Ce désir de partager l'information pousse plusieurs membres du personnel vers l'enseignement. Tout d'abord chargé de cours comme bien d'autres de ses collègues du Service, Carol Couture délaissera même le côté administratif pour devenir professeur afin de développer les programmes d'archivistique. II deviendra par la suite le directeur de l'École de bibliothéconomie et des sciences de l'information (EBSI) avant d'être nommé Conservateur et Directeur général des archives de Bibliothèques et Archives nationales du Québec (BAnQ). 
Mais l'implication du Service des archives ne s'arrête pas là puisque plusieurs de ses membres joueront un rôle actif dans les structures associatives de l'archivistique québécoise et canadienne. Le dynamisme du Service et de ses membres sera aussi reconnu à plusieurs reprises par l'attribution de différents prix par l'Association des archivistes du Québec.

Pour souligner ces cinquante années au service de l'archivistique, la Division de la gestion de documents et des archives a organisé un colloque mettant en lumière les différentes facettes de son histoire. Ce sont ces 50 ans de contribution exceptionnelle au développement de l'archivistique québécoise qui vous sont racontés, tout en émotion, au fil des pages qui suivent.

Bonne lecture.

\section{Diane Baillargeon}

Rédactrice en chef invitée à la revue Archives et Directrice, Division de la gestion de documents et des archives, Université de Montréal 